\title{
Símbolos y arquetipos en la trinidad protagonista de La Celestina
}

\author{
Daína Chaviano \\ Florida International University
}

La persistencia de un texto literario en la memoria cultural no ocurre a menos que éste contenga algún sustento psicológico profundamente vital para el ser humano. Es casi imposible hallar una de esas obras indelebles donde no aparezcan personajes cuya esencia los ha convertido en símbolos culturales colectivos. La tragicomedia de Calisto y Melibea, de Fernando de Rojas, incluye más de un elemento de esta clase, cuyo alcance llega a regiones psicológicas tan raigales que pertenecen al terreno del inconsciente colectivo. Aunque tales atributos no resulten evidentes tras una primera lectura, y ni siquiera después de un análisis más detenido -ya que los símbolos y los arquetipos suelen habitar en el ático del subconsciente-, no por ello su influjo deja de sentirse. Un texto que sigue siendo objeto de interminables conjeturas, medio milenio después de su aparición, que ha trascendido sus fronteras idiomáticas y culturales para marcar los orígenes del drama inglés (Ward) y ser el probable antecedente de una tragedia emblemática como Romeo y Julieta, podría justificar una pesquisa de esta índole.

En nuestro trabajo examinaremos las asociaciones arquetípicas que se ocultan en los nombres de los tres personajes principales de la obra de Rojas - Calisto, Melibea y Celestina-, como punto de partida para comprender la permanencia cultural de sus retratos psicológicos y posteriores destinos. Además, considerando la presencia de los símbolos y arquetipos asociados a ellos, y sus conexiones mítico-alegóricas, intentaremos mostrar cómo tales nombres determinan sus personalidades y anuncian el trágico fin de la trinidad protagonista celestinesca 


\section{What's in a Name?}

Las razones por las cuales se impone un nombre varían. Paolo Cherchi llama la atención sobre las diferencias entre los sistemas onomásticos que determinan la función de un apelativo. Por ejemplo, en el mundo mítico-primitivo todo nombre propio coincide con quien lo lleva, "pues el nombre es la persona misma, y por esto muchas veces se guarda secreto por miedo de que un enemigo lo utilice en prácticas mágicas». En nuestra sociedad occidental, el nombre tiene «en gran parte una función de identificación legal». En el mundo mágico-religioso, «evoca poderes ocultos». Por último, en la literatura "el nombre de un personaje tiene el sentido que el creador quiere darle» (Cherchi 77). Es en este terreno donde la importancia del nombre cobra una dimensión más definida:

Por lo general el autor impone los nombres a sus personajes pensando en describir a través de ellos su carácter o por lo menos unos rasgos destacados. La búsqueda del nombre para un personaje se basa a veces en recuerdos literarios, o se construye alrededor de elementos evocativos que pueden ser históricos, etimológicos o fónicos; y muchas veces el autor llega a crear verdaderos sistemas simbólicos, dando a los personajes de su obra nombres que en conjunto significan algo. Gracias a esta demiurgia los nombres propios en literatura tienen frecuentemente un poder connotativo que no se da en la lengua corriente. (Cherchi 78)

En ciertos casos, el nombre de un personaje puede contener incluso la negación de lo que éste representa, algo que suele ocurrir especialmente en obras de carácter paródico, satírico o humorístico. Esta negación puede coexistir con una afirmación de lo que constituye la naturaleza del sujeto, como veremos en los tres personajes principales del texto celestinesco. Para entender cómo puede ser posible esto, debemos repasar un par de conceptos.

En algún trabajo anterior, mencioné la existencia de dos niveles en los que se produce la creación literaria: uno lúcido, donde el autor tiene plena conciencia de lo que está introduciendo en su obra, y otro que escapa a su control, donde las ideas y los símbolos se deslizan desde su subconsciente para quedar atrapados en la propia historia (Chaviano 9, 16-17). Algunos investigadores que han estudiado el proceso creativo también concuerdan con esta percepción, cuando han señalado la importancia del subconsciente en la creación artística. Otros han propuesto variantes a la idea. Albert Rothenberg, por ejemplo, plantea la existencia de un mecanismo no-consciente, además del inconsciente: 
Repeatedly, artists of all types report that they cannot trace the steps in their achievement of outstanding ideas and that such ideas seem to intrude into their awareness without warning or preparation [...]. Here, however, I will insert a caution and a clarification regarding a distinction between the unconscious and the non-conscious [...]. Although we often use negations as though they were opposites, not tall is not synonymous with short, and not hot is not equivalent to cold [...]. Failure to recognize these differences has cause problems with respect to the idea and the term unconscious. (50-51)

Es vital, pues, entender que no siempre un proceso creativo no consciente es necesariamente inconsciente. ¿Cuál sería la diferencia entre creación inconsciente y no-consciente? Según nuestra propia experiencia, a través de un proceso de creación inconsciente, el autor da salida a rasgos reprimidos, ocultos o innatos de su personalidad. En cambio, el proceso de creación no-consciente parece estar más vinculado a la influencia de contextos sociales donde el autor incorpora la "autocensura» al proceso creador, ya sea por razones, religiosas, éticas o políticas. Esta "represión», que comienza siendo consciente, conduce finalmente a la inserción no-consciente de elementos vitales para el autor o creador, que éste se esfuerza por evitar, pero que ineludiblemente aparecen en la obra de una u otra manera.

Rothenberg, por su parte, también distingue dos mecanismos mediante los cuales se produce la secuencia creadora: el proceso janosiano y el proceso homoespacial. En el proceso janosiano - término derivado de Jano, el dios romano de los comienzos cuyos dos rostros miran en direcciones opuestas-, múltiples antítesis son concebidas simultáneamente para crear algo nuevo: "In an apparent defiance of logic or of physical possibility, the creative person consciously formulates the simultaneous operation of antithetical elements or factors and develops those formulations into integrated entities and creations» (Rothenberg 15). De este modo, la valoración de elementos contrapuestos da lugar a uno completamente nuevo.

El proceso homoespacial - término derivado del griego homoios (lo mismo) - consiste en que dos o más conceptos ocupan un mismo lugar, es decir, una misma idea o entidad contiene más de un significado. Lógicamente, "the homospatial process leads to effective literary double meanings» (Rothenberg 28). Para el análisis literario que nos ocupa, este segundo proceso resulta de particular importancia. Dada la dinámica del funcionamiento del subconsciente, sabemos que las asociaciones de orden simbólico - que aparecen, por ejemplo, en objetos de apariencia trivial dentro de una obra- podrían desvelar ciertas intenciones del creador. 
Por lo general, suele ocurrir con esa clase de elementos que un creador escoge sin pensar mucho, como los nombres de sus personajes. Por supuesto, puede existir un propósito consciente en su selección, pero detrás de cada decisión también hay vínculos de los que un autor no siempre es consciente.

Carl Gustav Jung observó que "los arquetipos no se difunden meramente por la tradición, el lenguaje o la migración, sino que pueden volver a surgir espontáneamente en toda época y lugar sin ser influidos por ninguna transmisión exterior» (Arquetipos 73). Por ello, el descubrimiento de algún elemento simbólico o arquetípico vinculado a los personajes de esta obra, podría ayudarnos a comprender mejor las características de un texto surgido en una época de transición, en la que los conceptos sobre el amor, la sexualidad y el matrimonio estaban en pleno tránsito evolutivo.

\section{A Name by any Other Name}

Lo primero que llama la atención cuando nos enfrentamos a La tragicomedia de Calisto y Melibea son los nombres de los personajes. Resulta extraña la inserción de semejantes nombres, casi todos de ascendencia "clásica», dentro de una obra que, en lo demás, se ajusta a los patrones de tiempo y lugar. Como señala humorísticamente Paolo Cherchi: «En la Celestina no hay ni un Paco ni un Pepe» (81). ¿Por qué bautizar de modo $\tan$ caprichoso a personajes tan representativos de sus respectivas clases sociales y que se mueven según costumbres bien definidas dentro de una época? Podríamos comenzar suponiendo que existió un propósito consciente en la selección de esos nombres. Si pensamos en el conocimiento mostrado por su autor o autores - para involucrar al anónimo iniciador del texto- sobre la literatura clásica precedente, no es arriesgado especular que existió una intención primaria consciente en esa selección.

Según el consenso general, Rojas escribió La tragicomedia a partir de la obra inconclusa de otro autor. ¿Es esto cierto? Y si es así, ¿mantuvo los nombres originales de los personajes o los cambió por otros? Es sólo su palabra contra ninguna. Pero incluso si Rojas no hizo más que continuar una historia ya comenzada, manteniendo los nombres originales, las claves para el desarrollo posterior de la trama ya vienen dadas desde el primer acto, donde aparecen casi todos. Recordemos que ya se ha señalado la posibilidad de que Rojas fuera un judío converso (Severin, 13-14), muchos de los cuales estaban familiarizados con la alquimia y la cábala. ¿Lo fue también el misterioso autor que originó el relato? El propio Rojas nos da una pista. En la carta incluida al principio de la obra, Rojas afirma que aunque el texto descubierto no contiene la firma de su autor, "algunos dicen, fue Juan de Mena, e según otros, Rodrigo Cota» (70). 
Vale recordar que Juan de Mena (1411-1456) fue un poeta cordobés pre-renacentista que estudió en la Universidad de Salamanca, la misma institución donde Rojas cursó sus estudios de Leyes. Entre sus obras se destaca el poema alegórico Laberinto de Fortuna, en cuyo argumento aparecen abundantes figuras mitológicas con una enorme carga alegórica. Varias fuentes señalan el probable origen judeoconverso del autor. Por su parte Rodrigo Cota fue un poeta toledano (siglo xv) de origen judío, incluido en alguna monografía sobre la literatura de los conversos de la España medieval (Kaplan). Así, pues, las tres únicas fuentes vinculadas al texto - Rojas, Mena y Cota - apuntan a una conexión hebrea. Y aunque nunca sabremos qué parámetros conscientes o no-conscientes siguió el primer autor para bautizar a sus personajes, no sería descabellado suponer - dados estos vínculos autorales en los que insiste Rojas- que podríamos realizar una lectura esotérica de los nombres que se hallan en el texto, inspirada en los mecanismos de la cábala hebrea. Es significativo que el acróstico — uno de los recursos más socorridos de la cábala para ocultar y/o jugar con el significado de los nombres- haya sido empleado por Rojas en los versos que aparecen al principio de la obra. Señalemos también que investigadores como Henk De Vries, citado por Severin, «llega a interpretar toda la obra como un enorme acróstico» (xxi, n. 33). No nos parece arriesgado conjeturar que alguien versado en literatura clásica, y posiblemente familiarizado con los textos alquímicos, decidiera incluir - quizás a un nivel no-consciente- nombres que proyectan asociaciones simbólicas sobre sus personajes. Recordemos que la alquimia se caracteriza por un lenguaje en clave, que oculta el significado de los procesos.

El primer indicio proviene del nombre de Calisto —adjudicado a un personaje masculino-, que significa "de gran belleza». Aunque el mancebo queda retratado como de "gentil dispositión» (Rojas, Prólogo 82), de «hermosura, gracia, grandeza de miembros, fuerça, ligereza» (i, 99), el significado de ese nombre no cumple ninguna función significativa. Según Cherchi, «su belleza se queda como un atributo vacío en la obra por cuanto no contribuye en nada a la acción: al contrario, sabemos que la conquista del amor de Melibea la debe no a su belleza sino a la mediación de Celestina» (82). Aunque la afirmación de Cherchi pudiera parecer demasiado absoluta, pues Melibea parece sentir una atracción previa hacia Calisto, lo cierto es que Rojas no insiste en la fisonomía del joven como elemento determinante de su conquista. En otras palabras, Calisto nunca se vale de su atractivo físico para conquistar a Melibea, sino que usa la mano interventora de Celestina.

Quizás, pues, habría que desechar esta primera lectura etimológica para continuar indagando en el verdadero propósito del nombre. Buscando en fuentes mitológicas, descubrimos que Calisto es el nombre de una de las ninfas favoritas de la diosa Artemisa. Resulta bastante extraña la 
idea de adjudicar un nombre femenino a un personaje masculino, especialmente teniendo en cuenta que los lectores potenciales del texto reconocerían de inmediato la incongruencia. Según el mito, Zeus adoptó la figura de Artemisa para hacerle el amor (o violar, según otras versiones) a Calisto, quien quedó embarazada del futuro Arcas. Cuando Artemisa - diosa extremadamente celosa de la virginidad de su séquito- descubrió el embarazo de Calisto, la expulsó de su compañía. Hera, esposa oficial de Zeus, que perseguía incansablemente a las amantes de su adúltero marido, también se vengó de esa infidelidad transformando en osa a la desdichada joven. Años después, Zeus la arrebató de la tierra junto con su hijo Arcas (nombre etimológicamente vinculado a Arktos, que significa "Oso»), en el instante en que éste, convertido ya en un joven cazador, se aprestaba a matarla. Zeus transformó al joven en oso, y lo colocó junto a su madre en el cielo, donde ambos forman las constelaciones de la Osa Mayor y la Osa Menor. Despechada, Hera pidió a Tetis, esposa de Océano, que jamás permitiera que estas constelaciones pudieran acercarse a sus aguas para buscar refugio en ellas (Noël 280, Commelin 87-88). El significado que encierra esto para nuestra tragicomedia es algo que veremos más adelante.

Según la percepción jungiana, todo animal asociado a la personalidad del hombre es una especie de código simbólico que «representa la psiquis no humana, lo infrahumano instintivo, así como el lado psíquico inconsciente» (Cirlot 73). Durante el proceso alquímico, se le da el nombre de "Oso" a la nigredo o primera etapa de la metamorfosis alquímica. La nigredo es la fase correspondiente al color negro, cuando la materia se encuentra en estado bruto y sin purifica. Es la etapa de la putrefacción o fermentación. Para Jung, esta nigredo (o negrura) representaba el momento de máxima desesperación como requisito previo a la iluminación espiritual, un estado que sólo se alcanza después de procedimientos muy complejos. En general, el oso puede ser considerado como un «símbolo del aspecto peligroso del inconsciente o como atributo del hombre cruel y primitivo" (Cirlot 344). Los lingüistas han concluido que el vocablo original proto-indoeuropeo de oso - ${ }^{*}$ rkso o sus variantes - significa "destructor», según indica el término sánscrito equivalente "rackshas», que significa «daño» o «herida»

El análisis que realiza Enrique Baltanás parece corroborar el vínculo entre la personalidad de Calisto y la mitología asociada a su nombre. Para ese investigador, Calisto no es el amante "tierna y poéticamente enamorado» del que hablan otros autores. Ya desde la primera escena, revela sus lujuriosas intenciones hacia Melibea. Incluso si ese polémico inicio fuera un sueño, según han apuntado investigadores como Miguel Garci-Gómez y Ricardo Castells, los verdaderos propósitos del personaje resultarían mucho más reveladores, dado que el sueño es el estado mental que 
abre la puerta al inconsciente y, por tanto, resulta un medio idóneo para que el instinto irrumpa con toda su fuerza.

Según apunta este autor, Calisto sólo quiere gozar del cuerpo de Melibea, y no pedirla en matrimonio. Las razones de su pretendido enamoramiento son harto carnales. Y «porque lo que busca es gozar del cuerpo de Melibea, recurre a la vieja alcahueta, y por eso no se le ocurre enviar a un familiar a pedir su mano» (Baltanás 6). Es por eso que el lector contemporáneo, engañado por el lenguaje que utiliza Calisto —quizás el único medio que conoce para expresar lo que siente, según señala Baltanás-, pudiera creer en su entusiasmo amoroso. Sin embargo, las intenciones del mancebo no confunden a sus congéneres:

...ni los criados de Calisto ni la vieja Celestina se engañan acerca de la naturaleza de la pasión que atormenta al joven [...] La pasión de Calisto no despierta admiración, simpatía, compasión o solidaridad a su alrededor, y no sólo porque criados y alcahueta pertenezcan a un mundo bajo social y moralmente, sino porque ninguno de ellos se engaña al respecto. Para ellos, desde luego, no se trata de amor noble y desinteresado, sino de lisa y llana apetencia sexual, llevada al extremo y singularizada en la sola persona de Melibea. (Baltanás 6-7)

A partir del momento en que Melibea accede a verlo en la intimidad, las acciones de Calisto contradicen sus galantes palabras y él se comporta con bastante rudeza. Cuando Melibea se dispone a entregarse y le pide a su criada Lucrecia que se retire, Calisto interviene con una insólita salida: "¡Por qué, mi señora? Bien me huelgo que estén semejantes testigos de mi gloria» (xiv , 285). Baltanás hace notar, con toda razón que «este comportamiento exhibicionista, y si se quiere, brutal, es lo más alejado del amor cortés que quepa imaginar. No hay rastro alguno de delicadeza en el comportamiento de Calisto precisamente en el momento en que éste va a arrebatar a la doncella 'el mayor don que la natura me ha dado'».

La actuación de Calisto como paradigma del amante cortés deja tanto que desear que ha sido notada por varios autores. Dorothy S. Severin ha planteado que "a través de Calisto, el autor estaría criticando al amante cortés -ya sea en su papel trágico, ya sea en el paródico» (24). Otros son más incisivos. Baltanás opina que, debido a su posición social, Calisto es un caballero que asume los refinamientos de su clase, contaminado por las nuevas teorías sobre el amor. Sólo por eso, su deseo «no puede conformarse con rameras y mujeres de baja estofa, como sus criados. Necesita a alguien más poético, que sepa cantar y tañer instrumentos, ataviada de ricos vestidos, perfumada de olorosos perfumes, fina de gestos y ademanes, alguien que sea una verdadera dama, equiparable a él» (15). 
Abrumado por este nuevo concepto del amor que va emergiendo, pero quizás aturdido aún por la visión medieval según la cual «una cosa era el sexo, otra el amor, y otra el matrimonio» (Baltanás 15), el joven no reacciona adecuadamente a los reclamos de su instinto. "Calisto - y éste es su drama - no es consciente de la verdadera naturaleza de sus sentimientos. Confundiendo sentimientos elevados con bajas pasiones, lo que hace en realidad es dorar y poetizar sus impulsos sexuales, que son los que lo mueven, y que nunca se transforman en verdadero amor» (Baltanás 15). De este modo, el deseo sexual de Calisto, disfrazado de solicitud amorosa, se convertirá en la torpe y desmañada ejecución de una satisfacción instintiva.

Aunque el joven intenta sublimar sus instintos a través de requerimientos caballerescos y socialmente aceptados, para él resulta demasiado prematuro asimilar esa mezcla. Faltará algún tiempo para que Occidente logre integrar saludablemente estos conceptos del amor y el sexo. Y si a primera vista las intenciones de Calisto no son evidentes, porque se encuentran camufladas tras el suntuoso bosque de frases caballerescas, su verdadero apetito continua allí, oculto, del mismo modo que el instinto animal se oculta tras el simbolismo mitológico de su nombre. En esa imagen del oso, asociada a la leyenda del nombre, subyace ese "hombre cruel y primitivo» que se alza, como la proverbial sombra jungiana, en el trasfondo psicológico del personaje. Así, pues, detrás de la fraseología elegante "del erótico egoísta Calisto» (Severin 26), sólo hay un puro y descarnado deseo sexual. En este sentido podemos reconocerlo como la parodia del amante cortés, casi una figura satírica dentro de esta tragicomedia.

\section{Frailty, Thy Name is Woman}

Melibea, por el contrario, resulta un personaje verdaderamente trágico. Para Severin, nos hallamos ante lo que parece ser el «retrato, bastante convincente, de una joven que se enamora locamente, hasta la perdición» (34). Incluso la etimología de su propio nombre es una alegoría de su condición femenina. Cherchi piensa que «el sentido de su nombre es transparente", gracias a la asociación con el pastor Melibeo de las Églogas virgilianas, y afirma que éste significa "de la voz melosa, dulce» (Cherchi 82). Para apoyar su tesis sobre ese vínculo, menciona el hecho de que la joven "canta por lo menos una vez en la obra» (Cherchi 82). Sin embargo, también reconoce que sólo canta mientras espera: «... es decir, en un momento de inacción. Su voz, como la belleza de Calisto, no determina de ninguna forma la acción de la obra. Al contrario, cuando Calisto llega y le ruega que siga cantando, ella rehúsa diciendo: ‘Por qué me dejabas echar palabras sin seso al aire, con mi ronca voz de cisne?'» (Cherchi 83). Meli- 
bea tampoco canta cuando, al premeditar su suicidio en lo alto de la torre, pide a su padre que le traiga algún instrumento. "Las últimas palabras y el último acto de Melibea contradicen, pues, los atributos que su nombre indica» (Cherchi 83). En este caso, como en el de Calisto, Cherchi no logra encontrar razón alguna que justifique la presencia de su nombre.

Pero hay otra raíz etimológica que nos remite, una vez más, a la simbología del mito. Melibea proviene del griego mely: «ocuparse, cuidar de», y de bois: «buey», es decir, Meliboios significa "que cuida de los bueyes» (Tibón 167). De ahí que el pastor en las Églogas de Virgilio haya tenido ese nombre. También se llama así una ninfa, hija de Océano y Tetis, que habitaba en las aguas.

¿Qué puede decirnos esta doble referencia? En primer término, recuérdese que la doncella Calisto, una vez transformada en osa y convertida en constelación, no puede - por decreto divino - volver a acercarse al océano: el lugar donde habita la Melibea mitológica, hija del dios de las aguas. Desde un principio, la raíz mitológica de ambos nombres parece señalar la imposibilidad de que ambos jóvenes permanezcan juntos. Regresando a la etimología pastoril del nombre Melibea ("que cuida de los bueyes»), debemos recordar que el buey siempre fue considerado en Grecia y Roma como atributo de la agricultura y de los fundamentos iniciales. Cirlot apunta que «en el Hortus Deliciarum, de Herrade de Landsberg, el carro de la luna es tirado por bueyes, lo que precisa el carácter feminizado del animal» y también que «en la emblemática medieval aparece con el citado significado de paciencia y sumisión o espíritu de sacrificio» (104). Si extendiéramos su significado al toro -o buey no castrado-, el animal posee una cualidad fuertemente vinculada a la feminidad, pues aparece como «símbolo de la tierra, de la madre y del principio húmedo» (Cirlot 445). Aunque luego el toro llegó a formar parte del culto mitraico o solar, ello sólo se debió a que el culto lunar -originalmente perteneciente al buey/toro del período agrícola de la civilización - fue vencido por el culto solar, que se apropió del símbolo. Pero el toro continúa siendo símbolo de la Luna "con la que se identifica morfológicamente por los cuernos y el creciente» (Cirlot 445). Por ello mantiene su carácter femenino. De ese modo, la imagen lunar de Melibea — vinculada a la feminidad paciente y reposada del buey - aparece como antípoda del joven Calisto, asociado al instinto infrahumano del oso mitológico. Esa diferencia marca el carácter y posterior destino de ambos amantes.

La muerte accidental de Calisto es una metáfora: la conclusión inevitable de ese instinto ciego que, al impedirle distinguir con claridad sus deseos, lo precipita a una caída fatal. Resulta, hasta cierto punto, una muerte tan grotesca como las pretensiones caballerescas con que el personaje disfraza su lujuria. En cambio, la muerte de Melibea es completamente premeditada y planificada. Ella es la joven instruida que ha logrado desarrollar ideas propias, según le explica a su padre antes de morir, «coligidas 
y sacadas de aquellos antigos libros que [tú], por más aclarar mi ingenio, me mandavas leer» (xx , 334). Esta «encerrada donzella» no ha permanecido tantos años en el hogar paterno, leyendo y ejercitando su imaginación por gusto.

Melibea ha alcanzado un estadio intelectual superior al de Calisto. Por eso es capaz de enamorarse, en el sentido moderno del término. La muchacha no disfraza su pasión con las frases bucólicas de su pretendiente. Claramente se refiere a su "amoroso desseo» (x, 238), una frase reveladora donde muestra que el amor y el sexo son conceptos que ella ha logrado fundir congruentemente. Y aunque ha tratado de guardar las formas, su espíritu "rechaza los modelos de comportamiento sexual de la época» (xx , n. 10), según hace notar Severin. Sin embargo, es de esperar que su sensibilidad, unida quizás a su prolongada doncellez, haya alimentado una «terrible pasión» (x, 238) que más tarde no la dejará sobrevivir la muerte de su amado. La convencional imagen de la fragilidad femenina encuentra en Melibea uno de sus paradigmas. No obstante, se trata de una fragilidad rebelde que protesta por el orden imperante: ${ }_{i} \mathrm{O}$ género femíneo, encogido y frágile! ¿por qué no fue también a las hembras concedido poder descobrir su congoxoso y ardiente amor, como a los varones?» (x, 239).

Esta es la gran diferencia entre Calisto y Melibea. Calisto profesa su deseo camuflándolo detrás de un lenguaje amoroso, mientras que Melibea profesa su amor aceptando la presencia del deseo. Como ha notado Baltanás:

La muerte voluntaria de Melibea confirma su entrega absoluta al amor; la de Calisto, accidental y algo ridícula, lo muestra definitivamente como esclavo de lo azaroso y efímero, de lo superficialy exterior. Su muerte no nos dice nada; o, mejor dicho, nos dice casi todo sobre ese casi nada - puro y simple deseo, si bien extremoso- que es Calisto. Melibea es humanamente superior a Calisto. Las respectivas muertes de ambos amantes ponen a cada uno en su lugar. (12)

Así, pues, Calisto - el mancebo con nombre femenino-y Melibea -la doncella con nombre de pastor - revelan, a través del género y la raíz de sus respectivos nombres, una naturaleza opuesta a la que pudiera evidenciar una primera ojeada. Calisto, la osa de carácter instintivo y salvaje, es un personaje frívolo y alocado por su ciego sometimiento ante el instinto; Melibea, el buey lunar de apariencia frágil y femenina, ha alcanzado una emotividad que supera las convenciones medievales y que la capacita para tomar decisiones osadas y racionales. Existe, sin duda, una creatividad homoespacial en la concepción de ambos nombres. En cada 
uno de ellos encontramos elementos opuestos que, al fundirse, logran enriquecer el retrato psicológico de sus dueños.

Vale destacar la coherencia psicológica arquetípica entre el ánima femenina de Calisto — cuya exaltada emotividad cuaja perfectamente en el símbolo de una osa-y el ánimus masculino de Melibea —encerrado en el símbolo del pastor "que cuida de los bueyes»— de fría y calculada racionalidad. No deja de resultar curioso que, cuatro siglos más tarde, Jung calificara al ánimus como el «pastor anímico» de la mujer (Jung, Aión 29). La riqueza conceptual de ambos personajes le debe mucho a este concertado equilibrio de elementos contrarios, surgido quizás del vínculo sutil que establece todo autor con las fuentes de la psiquis donde yacen los arquetipos del subconsciente colectivo.

Ahora bien, no debemos olvidar que el final de ambos personajes se produce por la intervención de un tercer elemento, sin cuya mediación no se habrían dado las condiciones para la reacción final. Este desenlace revelador, al cual se precipitarán las naturalezas disímiles de sus protagonistas, proviene de un ingrediente supremo que, al igual que ocurre con la obra alquímica, termina por producir — según el procedimiento Solve et Coagula - la coincidentia oppositorum: la fusión de los contrarios. Ese ingrediente supremo, que completa la fórmula alquímica de Rojas, es un tercer personaje que es también la antítesis de su nombre.

\section{This thing of darkness...}

La intervención de Celestina es el componente que sellará el destino de varios personajes en la obra, incluyendo los protagónicos. Su importancia es fundamental en el desarrollo y desenlace de la trama. No por casualidad el texto, cuyo título original era La tragicomedia de Calisto y Melibea, terminó por convertirse en La Celestina. Pero la magnitud del personaje va más allá de su intervención catalizadora.

Los nombres en esta obra son una «microversión de lo que ocurre en el macrotexto" (Cherchi 88), como ya hemos visto al analizar la etimología de Calisto y Melibea. En el caso específico de Celestina, el examen de su nombre no es menos revelador, conduciéndonos incluso a alegorías y conexiones de potencia arquetípica. Celestina proviene del latín caelestis (celeste), un adjetivo que evoca "mundos celestiales, angélicos, puros, es decir, todo lo contrario de lo que la alcahueta es» (Cherchi 84). Celeste fue también una deidad de los fenicios y los cartaginenses, que los griegos llamaban Urania, y que tenía el sobrenombre de Reina o Fortuna del Cielo (Noël, 314-15). Hagamos un paréntesis para recordar que Juan de Mena, a quien el propio Rojas propone como uno de los dos posibles padres de su obra, es el autor del poema alegórico Laberinto de Fortuna, un 
texto harto conocido por Rojas, a juzgar por sus numerosas alusiones al mismo, anotadas por investigadores como Julio Cejador y Frauca que lo considera un admirador del poeta cordobés.

Por otra parte, "Fortuna del Cielo», sobrenombre de la diosa Celeste, nos remite a la idea de la lectura astrológica que revela los destinos humanos. Existen vínculos entre la astrología, la alquimia y la cábala; algo que debió de influir en el proceso creativo de un autor judeoconverso de la época, aunque fuera de manera no-consciente. No profundizaremos más en este aspecto, pero vale la pena señalar que, si intentáramos la asociación del vocablo "celeste» por la vía astrológica, también llegaríamos al mismo resultado: Celeste o Celestial $\rightarrow$ Astros $\rightarrow$ Destino.

Además del nombre, existen otras claves que identifican la figura de Celestina con la fortuna y/o el destino. Por boca de la misma Celestina sabemos que ella siempre lleva su hilado (atributo del destino) como pretexto para entrar a las casas: "Aquí llevo un poco de hilado en esta mi faltriquera, con otros aparejos que conmigo siempre traygo para tener causa de entrar donde mucho no só conoscida la primera vez» (iii, 145). Si repasamos el mito, la diosa Destino tenía bajo sus órdenes a las tres Parcas —Cloto («hilar»), Laquesis («suerte») y Átropos («inflexible»)— cuya tarea consistía en tejer, tensar y cortar el hilo de la vida. La alegoría se extiende aún más porque ese hilado (o destino), con el que entra a casa de Melibea, ha quedado maldito tras un ritual de magia negra en el que la alcahueta establece un pacto con Plutón (iii, 147-48), el dios del mundo infernal. Si aceptamos el vínculo simbólico de Celestina con el destino, puede hacerse una lectura bastante significativa sobre la sucesión de acontecimientos que se desencadenan después que Melibea acepta el hilado diabólico.

Existe otro detalle de esa alegoría que se encuentra reflejado en la obra. Para simbolizar la inevitabilidad del destino, los antiguos lo representaban «por medio de una rueda fija con una cadena» (Noël 435). Y recuérdese que Calisto le regala a Celestina una cadena, a modo de pago, cuya presunta pérdida, que parece encubrir una negación a compartirla con Sempronio y Pármeno, provoca su propia muerte y, más tarde por concatenación, la muerte de éstos. Visto de ese modo, resulta una ironía — bien apropiada para una tragicomedia - que este objeto marque el destino inevitable de su poseedora y de quienes la anhelaban.

Sin embargo, Celestina representa algo más que una figura de predestinación. Existe un vínculo entre este personaje y la simbología de la Madre. A lo largo de la obra, la llaman así todos aquellos con quienes ella se relaciona para asuntos amorosos. La primera vez que un personaje se dirige a ella es Sempronio, quien la llama «madre bendita» (i, 104). Calisto se refiere a ella como "la madre» (i, 117). Este uso del artículo «la» para acompañar al vocablo «madre», en un momento tan temprano de la obra, parece establecer una identificación genérica con la figura materna 
Posiblemente la clave definitiva para esta caracterización quede registrada desde el primer acto, cuando Pármeno, al dolerse de la locura amorosa de su amo, que se postra lleno de adoración ante la Celestina, dice: " $\mathrm{O}$ Calisto desventurado, abatido, ciego! Y en tierra está adorando a la más antigua $[y]$ puta tierra, que fregaron sus espaldas en todos los burdeles» (i, 116). La frase "puta tierra» apenas deja dudas sobre la identific ción del personaje con el más universal de los arquetipos maternos. Y la asociación avanza así: Celestina $\rightarrow$ Madre $\rightarrow$ Madre Tierra.

No importa que Celestina aparezca como el lado oscuro de la maternidad. Como apuntara Jung, "todos estos símbolos pueden tener un sentido positivo, favorable, o un sentido negativo, nefasto" (Arquetipos 75). Celestina, obviamente, se adscribe al segundo grupo. Su intervención en el destino de los personajes - que se facilita ante la ausencia de una figura materna positiva - sienta las bases para la tragedia. Para James E. Burke, los finales trágicos de los personajes son resultado del metafórico «mal de la madre» centrado en Celestina, quien personifica todo lo opuesto a lo que implicaría una maternidad positiva (114). El «mal de madre» es un padecimiento que siguen tratando las curanderas del territorio español conocido como Castilla-La Mancha. La «madre» es la matriz o útero. "Se pensaba que el útero, es decir, la madre, de donde viene el mal, era capaz de conmoción y de él procedían los casos de histerismo, pues se suponía que dejaba su sitio natural y vagaba por donde quería, causando un agudo proceso histérico» (Blázquez 190).

Cuando Burke, quien cita diversas fuentes médicas dedicadas a estudiar el fenómeno, identifica a Celestina con el «mal de madre», establece también una correlación arquetípica importante. Celestina ofrece algunos remedios contra ese mal que sufre Areúsa, incluyendo una serie de sustancias con olores fuertes, lo cual «is completely in accord with the advice of ancient physicians, who believed that strong odors, both pleasant and unpleasant, could be effective in relieving symptoms» (Burke 112). Celestina sabe también que el remedio más eficaz contra ese padecimiento es el sexo y la maternidad. Pero cuando Areúsa, tras una noche de relaciones sexuales con Pármeno, se queja de que aún no se ha librado de su «mal de la madre» (viii, 211), el investigador cree reconocer en ello la maternidad negativa que representa Celestina: «Areúsa's 'wandering womb' serves as a symbol, which demonstrates the failure of affirmative maternal functions in Celestina» (Burke 114).

$\mathrm{Al}$ analizar el arquetipo de la Madre, Jung formula la existencia de dos aspectos opuestos: la madre amante y la madre terrible (Arquetipos 76). Cabe destacar también que, para él, la diosa del destino es un aspecto ambivalente de la figura materna, en tanto que la bruja es uno de los aspectos nefastos (Arquetipos 75). Ambas figuras se encuentran vinculadas al personaje que nos ocupa. En el primer caso, Celestina cumple cabalmente su papel de interceder entre los amantes, aunque esa intervención termina 
trágicamente. Ése sería su aspecto ambivalente. Pero también existe su identificación como bruja (recuérdese el ritual de magia negra del tercer acto): un aspecto negativo del arquetipo. Además, Celestina es llamada «vieja barbuda» (i, 103), «barbuda» (iii, 138) y «desvergonzada barbuda» (iv, 161), en lo que parece una alegoría física a la tradicional bruja, que suele ser una vieja con vellos en el mentón. Por extensión, esta barba también podría ser una alusión al macho cabrío del aquelarre y al propio demonio.

Los personajes aceptan a Celestina como la figura materna nominal. Piden su ayuda, y la mujer, ciertamente, se las brinda. Pero, de un modo $\mathrm{u}$ otro, eso termina por destruirlos: «Far from being a positive mother figure who secures the well-being of her children in both physical and metaphysical terms, the old woman initiates a course of action which brings ruin and destruction to those who have been foolish enough to seek metaphorical shelter under her mantle» (Burke 113-14). Y esa destrucción es la que confirma el arquetipo de la madre terrible a la que todos habían acudido en busca de ayuda y cuya intervención los conduce a la ruina.

Celestina logra usurpar el papel de Madre ante Melibea porque su contrapartida, Alisa, la madre biológica de la muchacha, desaparece en los momentos más importantes: desde que la alcahueta aparece por primera vez, en su casa, hasta los instantes previos al suicidio de Melibea. "Tu madre está sin seso en oýr tu mal; no pudo venir a verte de turbada» (xx, 330), dice Pleberio para explicar su ausencia en un instante crucial de la trama, cuando quizás un oportuno apoyo habría cambiado el ánimo y el destino de la muchacha. Pero Alisa nunca llega y, por tanto, no llega a convertirse en esa figura materna que hubiera podido contrarrestar el lado oscuro del arquetipo representado por Celestina.

Una variación interesante del aspecto de la madre terrible es el avatar de la diosa como madre devoradora, que los celtas representaron tan bien en la terrible Sheela-na-gig, una diosa que "ofrece la fantasía de excesos sexuales sin límite», pero que, a la vez, y curiosamente, "es recuerdo cómico [sic] de nuestros orígenes» (Sharkley 8). La estatuaria celta representa a la diosa Sheela-na-gig con un rostro de facciones cadavéricas y una enorme vulva que se abre desmesuradamente. Para Sharkley, «tales figuras, que expresan el misterio íntimo y conmovedor del nacimiento y simbolizan el momento en que la placenta se separa y nace una nueva vida, indican el profundo significado que acompaña el humor grotesco de algunos cuentos celtas» (8). Se trata de un humor incomprensible para la mentalidad actual, presente en muchas obras escritas o plásticas de la antigüedad:

Evidentemente, los gustos acerca de la comedia han cambiado en estos últimos cinco siglos y lo que entonces era entretenido, o divertidísimo, puede parecernos hoy 
cruel y, a veces, inaguantable, razón por la cual necesitamos notas a pie de página que nos expliquen los chistes. Indudablemente hay mucha crueldad en el humor de $\mathrm{La}$ Celestina. (Severin 23)

Ese humor primitivo y oscuro revela la presencia de la diosa arquetípica que, como Celestina, evoca la figura de la madre, aunque —en este caso- se trate de una madre destinada a devorar a sus propios hijos.

Al igual que ocurre con Calisto y Melibea, Celestina también lleva un sino contradictorio. La caracterización homoespacial contenida en su propio nombre representa el destino fatídico que aguarda a todos los que se arriman a su sombra y, en una doble ironía final de la tragicomedia, a la propia Celestina. Aunque encarna a la diosa Destino, ella misma es la primera en caer bajo la ineludible fatalidad del hado... lo cual nos recuerda el axioma mitológico de que ni siquiera los dioses son invulnerables al hilado de las Parcas. El doble simbolismo de Celestina - como destino y como madre terrible/devoradora- sirve de caja de resonancia que amplía su retrato psicológico y canaliza el desenlace de la trinidad protagonista donde ella está incluida. Su papel surge de las asociaciones implícitas en su nombre, igual que ocurre con Calisto y Melibea, cuyos nombres también contienen una duplicidad homoespacial: lo masculino instintivo versus lo femenino racional.

En cada caso, las asociaciones etimológicas parecen resumir las debilidades $y$, por ende, los peligros que acechan a sus correspondientes naturalezas. No es de extrañar que todos sigan una ruta predestinada por esos nombres. Este es el patrón que siguen también los cuentos de hadas, extensamente estudiados por Marie-Louise von Franz, para quien los destinos de los héroes y heroínas arquetípicos son expresiones de las dificultades y los peligros que nos suministra la naturaleza viii).

No sabemos si Fernando de Rojas fue consciente del significado oculto de esos nombres, pero las asociaciones arquetípicas encerradas en ellos parecen haber dirigido las acciones de sus personajes hasta el final. El vínculo judeoconverso del autor pudo influir notablemente en la asimilación de las alegorías y los símbolos culturales inscritos en esa onomástica. De cualquier modo, parecería como si la conducta y el trágico fin de la trinidad protagonista — determinados por la «biografía» mítica contenida en sus nombres - hubiera sido respetado por Rojas de manera no-consciente, siguiendo los tortuosos engranajes por los que atraviesa todo proceso creativo. Es posible que en este mecanismo de camuflaje y develación de conceptos arquetípicos — que todo lector realiza intuitivamente - radique uno de los motivos por los cuales La Celestina sigue alimentando nuestra avidez por revaluarla e interpretarla, una y otra vez, como un trágico cuento de hadas para adultos, contradictorio e infinito 


\section{Obras citadas}

Bal tanás , Enrique. "El matrimonio imposible de Calisto y Melibea (notas a un enigma)». Lemir: Revista Electrónica sobre Literatura Española Medieval y del Renacimiento 5 (2001): sin paginación. (http://parnaseo.uv.es/ Lemir/Revista/Revista5/Calisto/Calisto.htm)

Blázquez Miguel, Juan. Castilla-La Mancha: magia, superstición y leyenda. León: Everest, 1991.

Burke , James E. "The Mal de Madre and the Failure of Maternal Influence in Celestina». Celestinesca 17.2 (1993): 111-28.

Castells , Ricardo. "La primera escena de La Celestina: análisis y documentación del sueño de Calisto». (http://aaswebsv.aas.duke.edu/celestina/Celestina/ensa/escena1-Castells.htm).

Cejador y Frau Ca, Julio. Introducción. La Celestina, por Fernando de Rojas. Ed. Julio Cejador y Frauca. Madrid: La Lectura, 1913.

Cha viano , Daína. "Science Fiction and Fantastic Literature as Realms of Freedom». Journal for the Fantastic in the Arts 1.15 (2004): 4-19.

Cher Chi, Paolo. "Onomástica celestinesca y la tragedia del saber inútil». Cinco siglos de Celestina: aportaciones interpretativas. Ed. Rafael Beltrán y José Luis Canet. Valencia: Servei de Publicacions de la Universitat de Valencia, 1997. 77-90.

Cirlot , Juan-Eduardo. Diccionario de símbolos. Barcelona: Labor, 1985.

Co MMelin , P. Nueva mitología griega y romana. México: Divulgación, 1955. g ar Ci-g ó Mez, Miguel. "El sueño de Calisto». Celestinesca 9.1 (1985): $11-$ 22.

jung , C. G. Arquetipos e inconsciente colectivo. Barcelona: Paidós, 1991.

-. Aión. Contribución a los simbolismos del sí-mismo. Barcelona: Paidós, 1976.

kaplan , Gregory B. The Evolution of Converso Literature: the Writings of the Converted Jews of Medieval Spain. Gainesville: UP of Florida, 2002.

$\mathrm{n}$ oël , J. E. M. Diccionario de mitología universal. Barcelona: Edicomunicación, 1987.

t iBón, Gutierre. Diccionario etimológico comparado de nombres propios de persona. México: Fondo de Cultura Económica, 1991.

$\mathrm{r}$ ojas , Fernando de. La Celestina. Ed. Dorothy S. Severin. Madrid: Cátedra, 1987.

$\mathrm{r}$ othen Berg, Albert. Creativity and Madness. Baltimore: Johns Hopkins UP, 1990.

Severin, Dorothy S. Introducción. La Celestina. Fernando de Rojas. Ed. Dorothy S. Severin. Madrid: Cátedra, 1987.

$\mathrm{V}$ on Franz , Marie-Louise. The Interpretation of Fairy Tales. Boston: Shambhala, 1996.

Ward, Trent, et al. The Cambridge History of English and American Literature. Vol. 8. New York: G.P. Putnam's Sons, 1907-21. 


\section{Chaviano, Daína, "Símbolos y arquetipos en la trinidad protagonista de La Celestina», Celestinesca 30 (2006), pp. 9-25.}

\section{RESUMEN}

En el trabajo se examinan las asociaciones arquetípicas que subyacen en los nombres Calisto, Melibea y Celestina, los tres personajes principales de la obra de Rojas. Es probable que los arquetipos ocultos en sus nombres sean mecanismos no-conscientes que servirían para explicar sus retratos psicológicos. También se analiza la presencia de símbolos y arquetipos asociados a ellos, así como diversas conexiones mítico-alegóricas, para mostrar cómo esos nombres determinan sus personalidades y anuncian el trágico final de la obra

PALABRAS ClaVE: Celestina, Melibea, Calisto, arquetipo, alegoría, símbolo, onomástica, onomástico, Jung, subconsciente, mitología, madre, mitológico, cábala alquimia, destino, fortuna, ánimus, ánima, luna, lunar, bruja, celta.

\section{ABSTRACT}

This paper analyses the archetypical associations lying behind the three main characters names of de Rojas' work: Calisto, Melibea and Celestina. The archetypes hidden in their names may function as non-conscious mechanisms that would explain their psychological profiles. In exploring the symbology associated to those names, together with their mythical and allegorical connections, it is possible to explain their personalities and to foresee their tragic destinies.

KEY WORDS: Celestina, Melibea, Calisto, archetype, allegory, symbol, onomastic, onomastics, Jung, subconscious, mythology, mother, mythological, kabala, alchemy, destiny, fortune, animus, anima, moon, lunar, witch, celt, celtic.

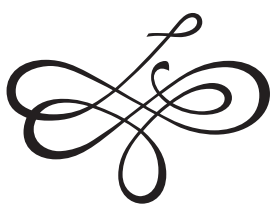




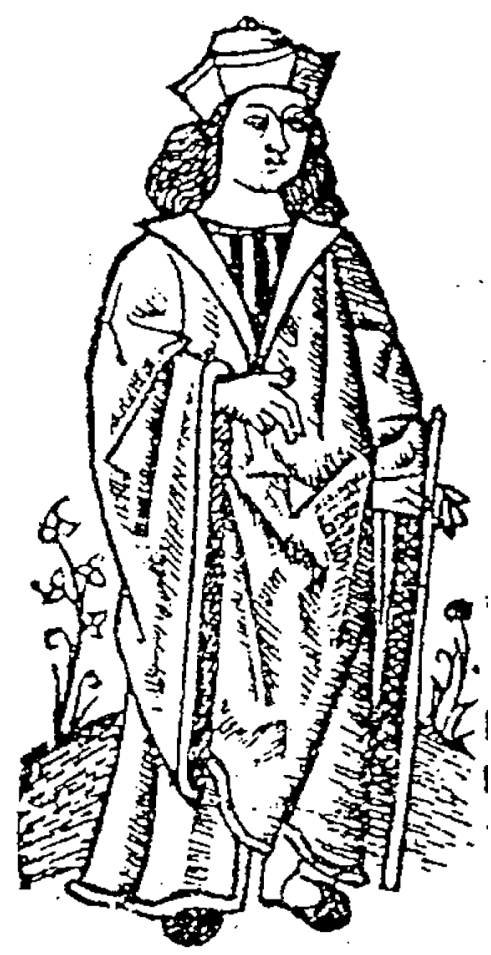

